\title{
Evaluation of strain accumulation in global subduction zones from seismicity data
}

\author{
Ryoya Ikuta ${ }^{1 *}$, Yuta Mitsui', Yuri Kurokawa² and Masataka Ando ${ }^{3}$
}

\begin{abstract}
We compared the cumulative seismic slip of interplate earthquakes $(\geq M 5.5)$ with relative plate motion at subduction zones. By assuming that each interplate earthquake occurred on a stick-slip patch, we used the slip history of each patch to calculate the interplate slip in the surrounding area. We considered that areas in which interplate earthquakes occurred but that had small cumulative slips compared with relative plate motion were accumulating strain, and we calculated the size of these areas. We first used this method to test the rupture areas of six M9-class interplate earthquakes that have occurred during the past 100 years. The cumulative seismic slip preceding and following the six earthquakes was smaller than the relative plate motion in the rupture areas of the earthquakes. We interpret the areas of slip-deficient stick-slip patches to be the rupture areas of future huge earthquakes. We applied the same procedure to global subduction zones and found that slip-deficient stick-slip patches with large spatial extents (equivalent to the rupture area of M9-class earthquakes) occur in an additional 25 locations. Considering that six M9-class earthquakes have occurred in the past 110 years and that the recurrence interval in each case is probably between a few hundred and a thousand years, it is not surprising that 25 regions globally are capable of producing M9-class earthquakes. These regions may be the most likely candidates for the rupture areas of future M9-class interplate earthquakes.
\end{abstract}

Keywords: Huge earthquake, Slip deficit, Subduction, Mega-thrusts, Stick-slip

\section{Introduction}

Although interplate earthquakes with magnitudes of $\geq 9$ (M9-class earthquakes) occur infrequently, they cause severe damage and fatalities over huge areas, as shown by the 2004 Sumatra (Mw 9.2) and 2011 Tohoku (Mw 9.0) earthquakes. Such earthquakes can rupture subduction zones along hundreds of kilometers and generate destructive tsunami waves. Evaluating the probability of M9-class interplate earthquakes in global subduction zones has been an object of seismology for decades.

Geodetic data are useful for monitoring the source regions of huge interplate earthquakes during interseismic periods. For example, several geodetic inversion studies using an on-land Global Navigation Satellite System (GNSS) network reported that the source region of the 2011 Tohoku earthquake had been locked from at least

\footnotetext{
* Correspondence: ikuta.ryoya@shizuoka.ac.jp

1 Graduate School of Science and Technology, Shizuoka University, Shizuoka, Japan

Full list of author information is available at the end of the article
}

1996 to 2003 before the occurrence of an M7-class earthquake (e.g., Ito et al. 2000; Nishimura et al. 2004; Suwa et al. 2006; Hashimoto et al. 2009; Loveless and Meade 2010). However, studies published prior to 2011 did not associate interplate coupling with an upcoming huge interplate earthquake because the GNSS observation period ( $\sim 15$ years) was thought to be too short to judge whether the interplate coupling was persistent or temporary. In fact, geodetic observations in the studies mentioned above were disrupted by the M7-class earthquake in 2003.

The degree of coupling between plates is also indicated by the spatio-temporal distribution of interplate earthquakes. For example, Yamanaka and Kikuchi (2004) analyzed source rupture processes and slip distributions for eight large earthquakes $(\sim \mathrm{M} 7.5)$ occurring in the past 80 years around the source region of the Tohoku earthquake and concluded that these earthquakes did not fully release the slip expected from the relative plate motion. In the aftermath of the 2011 Tohoku earthquake, the apparent low seismic coupling can be explained in terms of
Springer

(c) 2015 Ikuta et al. Open Access This article is distributed under the terms of the Creative Commons Attribution 4.0 International License (http://creativecommons.org/licenses/by/4.0/), which permits unrestricted use, distribution, and reproduction in any medium, provided you give appropriate credit to the original author(s) and the source, provide a link to the Creative Commons license, and indicate if changes were made. 
slip-deficit accumulation, which should be released by a huge interplate event (Fig. 1). Ikuta et al. (2012) compiled the slip history of M7-8-class earthquakes around the source region of the Tohoku earthquake, including those analyzed by Yamanaka and Kikuchi (2004), to show that their cumulative seismic slip was smaller than expected for the relative plate motion in the region (Fig. 1). The authors showed that the center of the slip-deficit distribution coincides with a region that experienced significant slip during the M9 earthquake and that the area of the slipdeficient region was larger than that of a persistently locked region that had been identified through inversions of GNSS data for the 15 years prior to the Tohoku earthquake. This result indicates that part of the rupture area of the huge interplate earthquake had been locked for several hundred years and had elastically deformed the surrounding region of the upper plate. Consequently, the effective relative motion between the overriding plate and the subducting plate around the locked area was broadly suppressed compared with other regions, thereby reducing the cumulative seismic slip of M7-8-class earthquakes. Even if the size and persistence of the locked area are debated, it is agreed that an M9-class earthquake requires a cumulative slip-deficit equivalent to its slip over its rupture area.

Although a deficit in cumulative seismic slip relative to plate motion is necessary for an M9-class earthquake to occur, not all slip-deficient areas are locked, as the plate interface has varying frictional properties. While some areas demonstrate stick-slip instability, others slip stably. The former is defined as a velocity-weakening frictional property and the latter as velocity-strengthening in the context of the rate- and state-dependent friction law (Dieterich 1979; Ruina 1983). Some areas even behave as conditionally stable, which accompanies the rupture of an adjacent stick-slip zone (Scholz 1998). Further parts show occasional slow slip, one of which, along a subducting plate, was first reported by Hirose et al. (1999). The frictional properties of a slow-slip area have been modeled in various ways. A deficit in cumulative seismic slip can also be explained by aseismic slip on a stable or conditionally stable interface. However, if the frictional properties on the plate interface do not change with time (i.e., the stick-slipping part essentially slips seismically), we can

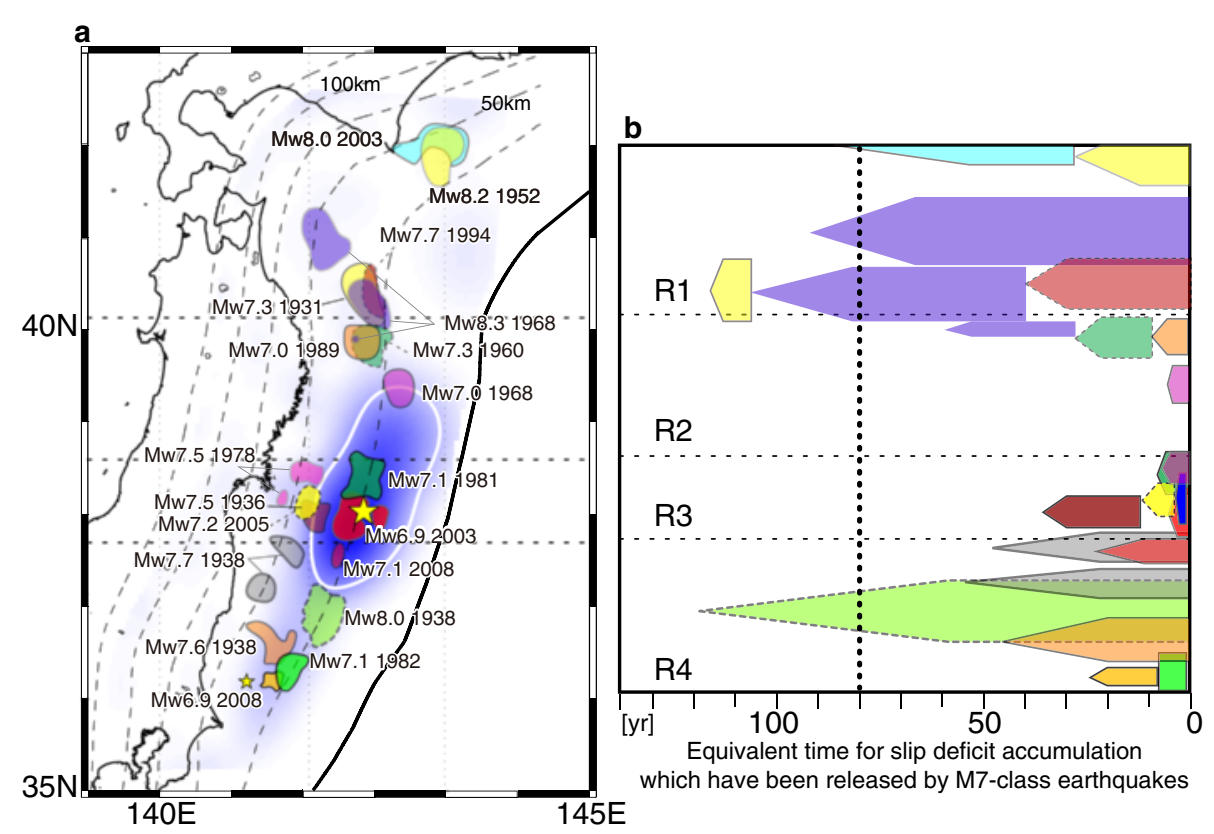

Fig. 1 Co-seismic slip of the 2011 Tohoku earthquake and previous M7-class earthquakes around the source region (after Ikuta et al. 2012). a Co-seismic slip distribution of the 2011 Tohoku earthquake (blue color scale); the area with slip greater than $10 \mathrm{~m}$ is enclosed by a white line. The two stars show the locations of the main shock and the largest after-shock (March 11, 2011). The asperity distribution for M7-class earthquakes occurring in the past 80 years is shown by colored contours (after Murotani et al. 2004; Yamanaka and Kikuchi 2004; Yamanaka (NGY Seismology Notebook, http://www.seis.nagoya-u.ac.jp/sanchu/Seismo_Note, last updated November 25, 2015)). The contour for each asperity encloses the area in which the slip is greater than half of the maximum slip. $\mathbf{b}$ Cumulative seismic slip distribution along the trench for the earthquakes shown in a. The total length of each arrow represents the maximum slip of the event, and the length of the body of each arrow represents the average slip. Modified after Figure 12b in Yamanaka and Kikuchi (2004), with the addition of the following: data for the 1952 and 2003 earthquakes off Tokachi in the northern part of the trench are from Yamanaka and Kikuchi (2003); data for earthquakes in 1938 and 1982 in the R4 region are from Murotani et al. (2004) and Mochizuki et al. (2008), respectively; and data for recent earthquakes are from Yamanaka, NGY Seismology Notebook, http://www.seis.nagoya-u.ac.jp/sanchu/Seismo_Note, last updated November 25, 2015. Slip on spatially overlapping asperities is accumulated. Vertical dotted line shows the total expected tectonic slip over 80 years 
estimate the slip deficit from the seismic slip history of the stick-slip patches.

Previous studies have shown the persistence of the stick-slip property of the plate interface for earthquakes of various sizes. For example, studies of repeating M2-4 earthquakes have revealed cumulative seismic slips that are consistent with the slips of the plate interfaces around the earthquakes (e.g., Matsuzawa et al. 2002; Igarashi et al. 2003). Uchida et al. (2005) showed that the same behavior occurs for larger earthquakes and that the recurrence interval of a characteristic M4.8 earthquake off Kamaishi, Japan, is controlled by the interplate creep rate in the surrounding area. Their result is explained in terms of a time-predictable model in which the isolated stick-slip patch slips when the loaded stress exceeds its strength. They suggested that the M4.8 source area should be stuck during the interseismic period and should slip unstably when the loaded stress exceeds its strength. Based on an analysis of small repeating earthquakes, Uchida and Matsuzawa (2011) also evaluated the distribution of interplate coupling around the source area of the Tohoku earthquake. They found a good spatial correlation between the area of the coupled region prior to the Tohoku earthquake and the area of large co-seismic slip. Yamanaka and Kikuchi (2003) analyzed the source rupture processes of two much larger earthquakes: the 1952 M8.1 earthquake and the 2003 M8.0 earthquake, both off Tokachi. The rupture areas of the two earthquakes are nearly identi$\mathrm{cal}$, and the 5-m seismic slip of the 2003 event is consistent with the slip deficit accumulated over the 51 years from 1952 to 2003, assuming a subduction rate of $\sim 10 \mathrm{~cm} /$ year.

In the above studies, the slip of earthquakes of various sizes is regarded as an indicator of slip on the surrounding plate interfaces. In this paper, we apply this concept to global subduction zones to identify regions with the potential to generate M9-class earthquakes. For each interplate earthquake up to M8, we assume that a stick-slip patch exists and we evaluate the interplate slip deficit by comparing the cumulative slip of each patch with the relative plate motion. From the areas of the patches that are accumulating slip deficit, we calculate the areas in which strain is accumulating due to the locked regions that are potential source areas of huge interplate earthquakes. Note that we do not evaluate the cumulated slip deficit itself but instead evaluate the spatial extent of the area dominated by slip-deficient stick-slip patches.

\section{Methods: evaluation of a 110-year-long slip deficit}

To study slip deficit on a plate boundary, we first define the plate boundary configuration and then identify stickslip patches of interplate earthquakes using the centroid moment tensor solution catalog provided by the Global CMT (GCMT) project (Dziewonski et al. 1981; Ekström et al. 2012). We then trace the slip history of these stick- slip patches using the ISC-GEM Global Instrumental Earthquake Catalogue (ISC-GEM catalog; Storchak et al. 2013) to evaluate the slip deficit. Finally, we evaluate the extent of the area in which slip deficit has accumulated by comparing the seismic slip with the relative plate motion. The spatial extent of the slip-deficient area is regarded as the size of a hidden, potential earthquake rupture area. The specific steps employed in this analysis are described below and shown in the flowchart in Fig. 2.

\section{Plate boundary configurations}

First, we defined the plate boundary configuration using the slab surface geometry constructed by Gudmundsson and Sambridge (1998). In mapping stick-slip patches on the plate boundary, we considered patches shallower than the Moho depth of the overriding plate to be available in the slip-deficit evaluation. Even if the sub-Moho mantle was seismogenic, the viscous flow of mantle wedge beneath the Moho would be likely to release at least some tectonic stress by viscous relaxation for rheologies constrained by experimental mineral physics data (e.g., Hirth and Kohlstedt 2003). We adopted $35 \mathrm{~km}$ as the Moho depth. In the actual procedure, we implied the $50 \mathrm{~km}$ depth by Gudmundsson and Sambridge (1998) to be $35 \mathrm{~km}$ according to Syracuse and Abers (2006), which pointed out that the slab surface contours of Gudmundsson and Sambridge (1998) tend to be shifted downwards compared with slab seismicity by $\sim 15 \mathrm{~km}$ at a depth of $50 \mathrm{~km}$. We placed grid points at $10-\mathrm{km}$ spacing at depths shallower than $50 \mathrm{~km}$ on the plate boundaries of Gudmundsson and Sambridge (1998) and calculated the interplate slip history at each of the grid points.

\section{Stick-slip patch map constructed from the GCMT catalog}

We extracted interplate earthquakes that occurred during the assigned period from the GCMT catalog, which lists earthquakes of $M \geq 5.5$ that have occurred since 1976. We define interplate earthquakes as those located on the slab surface with the following properties: dip angle of $<30^{\circ}$; plunge of the $N$ (neutral)-axis, which is the intersection of the two nodal planes, of $<15^{\circ}$; and direction of the $T$ (tension)-axis within $\pm 45^{\circ}$ of the direction of relative plate motion.

To construct the map of stick-slip patches from the extracted interplate earthquakes, we convert seismic moments to slip and rupture size. The seismic moment $M_{0}(\mathrm{Nm})$ is calculated from the moment magnitude $M_{w}$ under the relation derived by Hanks and Kanamori (1979):

$$
\log M_{0}=1.5 M_{W}+9.1
$$

From the definition of seismic moment (Aki 1966), the average slip $D_{\text {ave }}$ over the rupture area is 


\section{a}

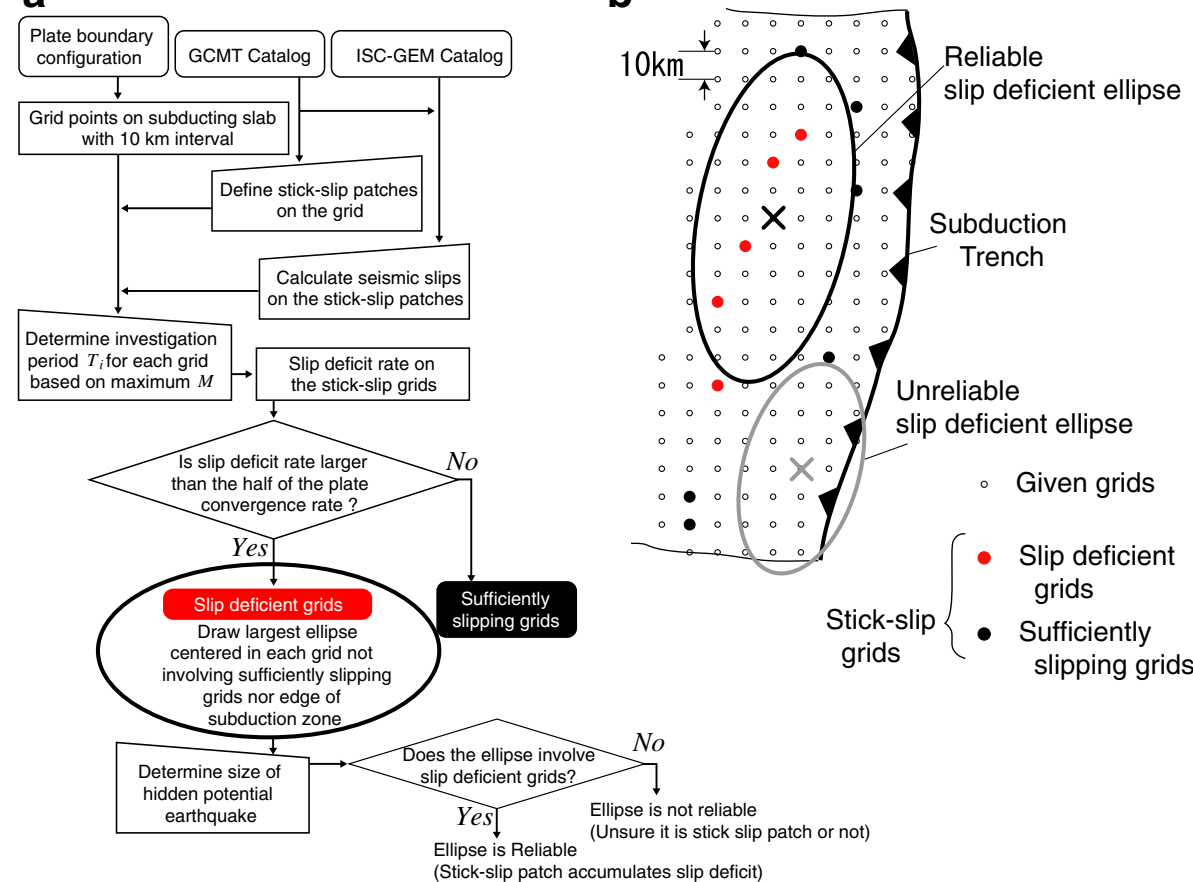

Fig. 2 a Flowchart of our analysis. We use plate boundary configurations, the GCMT catalog, and the ISC-GEM catalog as input data. Grid points are set on the plate boundary at 10-km intervals. We analyze interplate earthquakes from the GCMT catalog. On the plate boundary, we define stick-slip patches according to the magnitude of the interplate earthquakes using Eqs. 1, 3, and 4. The seismic slip of the patches is calculated at the grid points based on the magnitudes of the GCMT and the ISC-GEM catalog earthquakes. The cumulative seismic slip on the stick-slip grid points is divided by the period of investigation, yielding the slip rate. The plate convergence rate minus the slip rate is defined as the slip-deficit rate on each stick-slip grid point. If the slip-deficit rate is larger than half of the relative plate motion, the grid point is regarded as a "slip-deficient grid"; otherwise, it is a "sufficiently slipping grid". The largest elliptical area that contains no sufficiently slipping grid points is regarded as the area of hidden potential earthquakes. $\mathbf{b}$ Schematic illustration of the estimation of hidden potential earthquakes. The red and black solid circles show "slip-deficient" and "sufficiently slipping" grid points, respectively. The black open ellipse centered the grid point shown by a cross is an example of source area estimation for hidden potential earthquakes. This ellipse contains four "slip-deficient" grid points. The gray open ellipse is an example of an unreliable ellipse as it does not contain any "slip-deficient" grid points and is terminated by the edge of the plate boundary. Each grid point has an ellipse drawn in the same way

$$
M_{0}=\mu S D_{\text {ave }}
$$

where $\mu$ is rigidity expressed in $\mathrm{Pa}$, and $S$ is rupture area in square meter. The rigidity is assumed to be $30 \mathrm{GPa}$ in this study. The relationship between the area and slip of interplate earthquakes was studied by Murotani et al. (2008) using strong motion seismic records, yielding the following scaling relationship between $S$ and $M_{0}$ :

$$
S=1.48 \times 10^{-4} M_{0}^{2 / 3}\left(\mathrm{~m}^{2}\right) .
$$

Since Murotani et al. (2008) did not consider the aspect ratio of the rupture area, we derived the relation between length $L(\mathrm{~m})$ and width $W(\mathrm{~m})$ of the fault as

$$
L=0.1650 W^{1.239}
$$

from Blaser et al. (2010), in which the $L$ and $W$ were independently related to $M_{W}$. The width, length, and average slip of each earthquake can therefore be derived from the earthquake's magnitude using Eqs. 1, 2, 3, and 4. The slip distribution during each rupture must be assumed to evaluate the slip history of the slab surface. Though many other studies have reported a scaling relationship between $M_{0}$ and $L, W$, and average slip (e.g., Geller 1976; Wells and Coppersmith 1994), a characteristic shape of slip distribution has not been proposed. Murotani et al. (2008) defined the asperity as the area in which the slip of an earthquake is $>1.5$ times the average slip over the whole rupture area. In this study, we interpret this asperity as a stick-slip patch. This showed that the asperity occupies about $1 / 5$ of the rupture area and its average slip is 2.2 times that of the whole rupture area. As a simple function, we define slip distribution by the following Gaussian function (Fig. 3a):

$$
D=D_{\max } \exp \left(-\frac{x^{2}}{0.29^{2} L^{2}}-\frac{y^{2}}{0.29^{2} W^{2}}\right)(\mathrm{m}),
$$



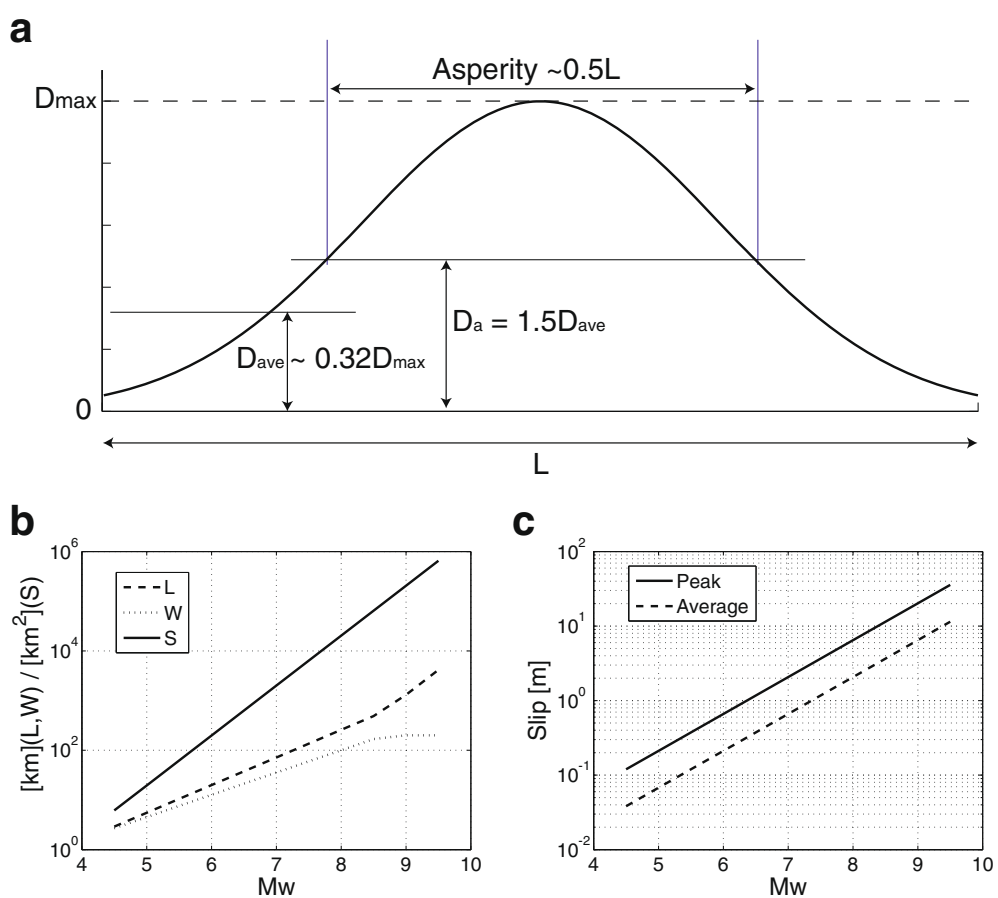

Fig. 3 Slip distribution and adopted scaling law of interplate earthquakes. a Gaussian slip distribution defined along fault strike. b Scaling relationships between fault area (solid line), fault length (dashed line), fault width (dotted line), and earthquake magnitude. Values are expressed in kilometer scale for readability. c Scaling relationships between the peak (solid line) and average slip (dashed line) of earthquake faults and earthquake magnitude

where $x$ and $y$ are the distances along strike and dip from the centroid, respectively. The coefficient $0.29^{2}$ is adjusted to satisfy Murotani's relation. For an elliptical fault, the area $S$ is $\frac{\pi}{4} L W$. From Eq. 5, $D_{\max }$ is 3.1 times $D_{\text {ave. }}$ By substituting $D_{\text {ave }}$ (as derived from Eqs. 2 and 3) into Eq. 5, the slip distribution can be calculated for a given $M_{W}$ (Fig. 3b, c). We define the inner area of an ellipse with long and short axes $L / 2$ and $W / 2$, respectively, as a stick-slip patch. In our analysis, we assume that the along-dip length of the slipping area $W$ does not exceed $250 \mathrm{~km}$, which is the largest-ever seismologically recorded width and was recorded for the 1964 Alaskan earthquake (Christensen and Beck 1994). Note that this cutoff does not affect the estimation of the cumulative seismic slip of cataloged earthquakes because all such earthquakes have $W<250 \mathrm{~km}$. This cutoff affects the calculation of the magnitude of the hidden potential earthquakes from the spatial extent of the slip-deficient area, as described in the "Estimation of the size of potential rupture area hidden behind slip-deficient stick-slip patches" section. However, this impact is minor, and a change in the cutoff value of $100 \mathrm{~km}$ only results in a change in the estimated magnitude of a $\sim$ M9 potential earthquake of 0.1 . This cutoff is employed solely to avoid unrealistically large magnitude estimates.
The fault slip distribution and stick-slip patch are calculated using the above procedure using the GCMT catalog. Hereafter, grid points included in the stick-slip patches are called stick-slip grid points.

\section{Slip accumulation and slip-deficit rate on stick-slip patches deduced from the GCMT and ISC-GEM catalogs}

Cumulative seismic slip was estimated for the stick-slip grid points. The cumulative seismic slips of each stickslip grid point for the earthquakes listed in the GCMT catalog were calculated by applying Eqs. 2, 3, 4, and 5 to each earthquake.

We used the ISC-GEM catalog to estimate the slip for the period before the beginning of the GCMT project, which started as the Harvard CMT in 1976. The ISCGEM catalog is a global catalog of hypocenter locations and magnitudes of instrumentally recorded earthquakes from 1900. We calculated the cumulative seismic slip on each grid point for the cataloged earthquakes in the same way as for those in the GCMT catalog, although for the ISC-GEM catalog the center of slip (the origin of $x$ and $y$ defined in Eq. 5) is the earthquake hypocenter rather than the centroid. From the cumulative seismic slip, the slip-deficit rate $U_{j}$ is defined for the $j$ th grid point as follows: 


$$
U_{j}=C_{j}-\frac{\sum_{i}^{N} D_{j i}}{T_{j}},
$$

where $C_{j}$ is relative plate motion speed (meters/year) on the $j$ th grid point, derived from Bird (2003). $D_{j i}$ is seismic slip (meters) on the grid point by the $i$ th earthquake, and $T_{j}$ is the total period of interest, which varies among different grid points. To evaluate the rate of slip deficit using the catalogs, it is necessary to consider two ways in which the catalogs are deficient. The first deficiency is in the record of smaller earthquakes during the early years of the ISC-GEM catalog, when cutoff magnitudes were $7.5,6.25$, and 5.5 for the periods prior to 1918 , from 1918 to 1959, and after 1959, respectively. To compensate for this incompleteness, we defined different total periods of the earthquake history, $T$, for different stick-slip grid points depending on the maximum earthquake size for each grid point. The stick-slip grid points with maximum earthquake sizes smaller than 6.25 , from 6.25 to 7.5 , and larger than 7.5 are evaluated for the periods starting in 1960, 1918, and 1900, respectively. Since larger earthquakes have longer recurrence intervals, it is reasonable that the stick-slip grid points in stick-slip patches that are capable of producing larger earthquakes should be evaluated using longer time periods. The second deficiency is a lack of mechanism information since fault types are only known for the period when the GCMT catalog is available. Outside of this period, we selected earthquakes with estimated source areas that include stick-slip patches identified from the GCMT catalog and treated them as interplate earthquakes. This assumption results in an overestimation of cumulative slip due to miss-classification of intraplate earthquakes as interplate earthquakes and therefore results in an underestimation of the resulting slip deficit of the grid point. The implications of this underestimation are discussed in the "Validity of assumptions" section.

Errors in estimating the locations of epicenters in the cumulative slip estimation can be important. The center of the slip is simply defined by the epicenter of each earthquake; however, since errors in epicenter locations are $\sim 5-15 \mathrm{~km}$, we do not adopt the epicenter location as the center of the ellipse for small earthquakes. We define the centers of the slip distribution ellipses for earthquakes of $<\mathrm{M} 6.25$ with short diameters of $<15 \mathrm{~km}$ as the closest stick-slip grid point within $15 \mathrm{~km}$ of the earthquake's epicenter. This procedure minimizes the apparent accumulation of slip deficit on small stickslip patches caused by uncertainties in the epicenter location.

Based on the above procedure, we estimated the slip and then the slip deficit of the stick-slip grid points using the GCMT catalog and the ISC-GEM catalog.

\section{Estimation of the size of potential rupture area hidden behind slip-deficient stick-slip patches}

We estimated the slip deficit around the source area of the 2011 Tohoku-Oki earthquake from the GCMT and ISC-GEM earthquake catalogs. Figure 4 shows the estimated cumulative slip of the stick-slip grid points from 1900 to 2010 around the source area of the 2011 Tohoku earthquake, superposed on the slip distribution for M7-class earthquakes occurring in the past 80 years deduced from strong motion records (after Murotani et al. (2004), Yamanaka and Kikuchi (2004), and Y. Yamanaka (NGY Seismology Notebook, http://www.seis.nagoya-u.ac.jp/sanchu/ Seismo_Note, last updated November 25, 2015)). The estimated slip distribution correlates well with that deduced from seismic records, although with a few exceptions such as the lack of slip estimated from strong motion around $36^{\circ} \mathrm{N}$ and $42^{\circ} \mathrm{N}$. We attribute the difference around $36^{\circ} \mathrm{N}$ to the incompleteness of slip distribution analyses for old earthquakes. In this region, six large earthquakes with magnitude $\geq$ M6.8 that occurred before 1968 are listed in the ISC-GEM catalog. We attribute the difference around $42^{\circ} \mathrm{N}$ to underestimation of the 1952 earthquake off Tokachi by strong motion data due to scaling out of the seismograms (Yamanaka and Kikuchi 2003). Since our estimation of cumulative slip using earthquake catalogs seems to be as accurate as previous estimations using strong motion records, at least along the Japan trench, we applied this cumulative slip estimation technique to the area for which historical strong motion records are unavailable. Using the estimated cumulative

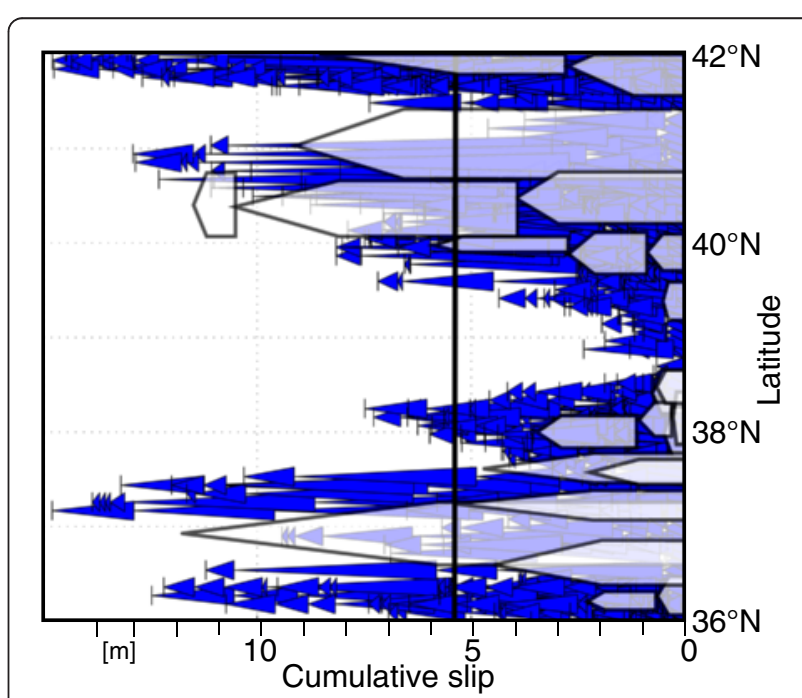

Fig. 4 Cumulative seismic slip for the 110 years preceding the 2011 Tohoku earthquake. Blue triangles are cumulative slip calculated from the GCMT and ISC-GEM catalogs. The superposed translucent pentagon-shaped patches are cumulative slip deduced from strong motion records, after Ikuta et al. (2012). The solid vertical line denotes half of the cumulative relative plate motion over the past 110 years 
slip, we estimated the rupture area of a hidden potential earthquake from the spatial extent of slip-deficient stickslip patches. First, we defined the stick-slip grid points with slip-deficit rates (Eq. 6) larger than half of the relative plate motion speed as "slip-deficient" and those with rates smaller than half of the relative plate motion speed as "sufficiently slipping". Next, centering each grid point, we drew the largest possible ellipse, with long and short radii corresponding to $L / 4$ and $W / 4$ (Eq. 5), respectively, which does not include any sufficiently slipping grid points. Each ellipse is terminated by either a sufficiently slipping grid point or by the end of the subduction zone under the condition that the diameter of the long axis of the ellipse is $\leq 1400 \mathrm{~km}$ (corresponding to the rupture size of an M9.5 earthquake by the scaling relationship of Eqs. 3 and 4). We calculated the earthquake magnitude from the size of the ellipse through the scaling relationship defined by Eqs. 1, 3, and 4 (e.g., the diameter is $440 \mathrm{~km}$ for M9 events and $110 \mathrm{~km}$ for M8 events). The calculated magnitude corresponds to that of an earthquake that ruptures the whole area enclosed by the ellipse as its asperity. If the ellipse is in contact with or contains stick-slip grid points of past earthquakes with magnitudes greater than that calculated from the size of the ellipse, the calculated magnitude is replaced by that of the past earthquake and the resulting magnitude is regarded as "reliable". Otherwise, the calculated magnitude is retained. The calculated magnitude is regarded as "unreliable" when no stick-slip grid points are included within the ellipse, since in this case it is not possible to judge whether the lack of stick-slip grid points reflects the absence of a stick-slip patch (i.e., the fault slips aseismically) or an accumulation of slip deficit on a hidden stick-slip patch, which would cause future interplate earthquakes.

By applying the above procedure to all grid points on the slab surface shallower than $35 \mathrm{~km}$, we estimated the locations of source areas of potential earthquakes.

\section{Results}

Spatial extent of "slip-deficient" grid points prior to three M9-class earthquakes in the past decade

We tested the proposed method by applying it to the source areas of the M9-class 2011 Tohoku, 2004 Sumatra, and 2010 Chile earthquakes using the earthquake catalogs prior to the three events. The available catalog periods for the 2011 Tohoku earthquake and the 2004 Sumatra earthquake extend from 1900 to one month prior to each earthquake. For the source area of the 2010 Chile earthquake, we used the catalog for the period from January 1961 to January 2010 because the 1960 Chile earthquake (Mw9.5) occurred in the area adjacent to the 2010 event. The calculated slip for the 1960 Chile earthquake is $46 \mathrm{~m}$, which corresponds to the cumulative relative plate motion for $\sim 460$ years, assuming a plate convergence rate of $10 \mathrm{~cm} /$ year. Our method is designed to evaluate the spatial extent of slip deficit using earthquakes with slip less than the cumulative convergence within the catalog period, as further discussed in the "Validity of assumptions" section. Therefore, we estimated the slip deficit before the 2010 earthquake using the catalog after the 1960 huge interplate event.

Figure $5 \mathrm{a}-\mathrm{c}$ shows the distribution of the calculated magnitude around the rupture areas of the three M9-class events. Around the rupture area of the 2011 Tohoku earthquake (Fig. 5a), the calculated magnitude is $>9.0$ along the up-dip end of the plate boundary between $36^{\circ} \mathrm{N}$ and $39^{\circ} \mathrm{N}$, which coincides with the area of large slip in the 2011 Tohoku earthquake. Other areas with a calculated magnitude of $>9.0$ along the Japan trench and its extension are located along the Kuril trench centered on $41^{\circ} \mathrm{N}$ and the Izu-Bonin trench at $\sim 30^{\circ} \mathrm{N}$. Around the source area of the 2004 Sumatra earthquake (Fig. 5b), the area with a calculated magnitude of $>9.0$ extends from $5^{\circ} \mathrm{S}$ to $15^{\circ} \mathrm{N}$. However, most of these grid points do not have slip-deficient grid points inside their ellipses and the reliability of the slip deficit is low. For the 2010 Chile earthquake (Fig. 5c), the calculated magnitude is $>9.0$ in the area between $35^{\circ} \mathrm{S}$ and $45^{\circ} \mathrm{S}$, which includes the source areas of the 1960 and 2010 earthquakes.

\section{Spatial extent of "slip-deficient" grid points after M9-class earthquakes of the 20th century}

We applied the same procedure as that detailed in the previous section to the rupture areas of the two other M9-class earthquakes that occurred in the 20th century; i.e., the 1952 Mw9.0 Kamchatka earthquake and the 1964 M9.2 Alaska earthquake (in addition to the 1960 Mw9.5 Chile earthquake). However, in this analysis we used the catalog following the M9-class events instead of preceding them.

Figure 5c-e shows the spatial distributions of calculated magnitudes around the rupture areas. Around the rupture area of the 1952 Kamchatka earthquake (Fig. 5d), the calculated magnitude is $>9.0$ between $48^{\circ} \mathrm{N}$ and $52^{\circ} \mathrm{N}$, which coincides with the rupture area of the 1952 Kamchatka earthquake. Around the rupture area of the 1964 Alaska earthquake (Fig. 5e), the magnitude is $>9.0$ from $160^{\circ} \mathrm{W}$ to $140^{\circ} \mathrm{W}$ and significantly protrudes westward from the rupture area of the earthquake defined by Christensen and Beck (1994). This result may indicate the existence of another source area for a huge earthquake adjacent to the area that ruptured in 1964. The result around the source area of the 1960 Chile earthquake is described in the previous subsection (Fig. 5c). The magnitudes of the six M9-class events are consistent with those expected from the spatial extents of the slip-deficient grid points. 


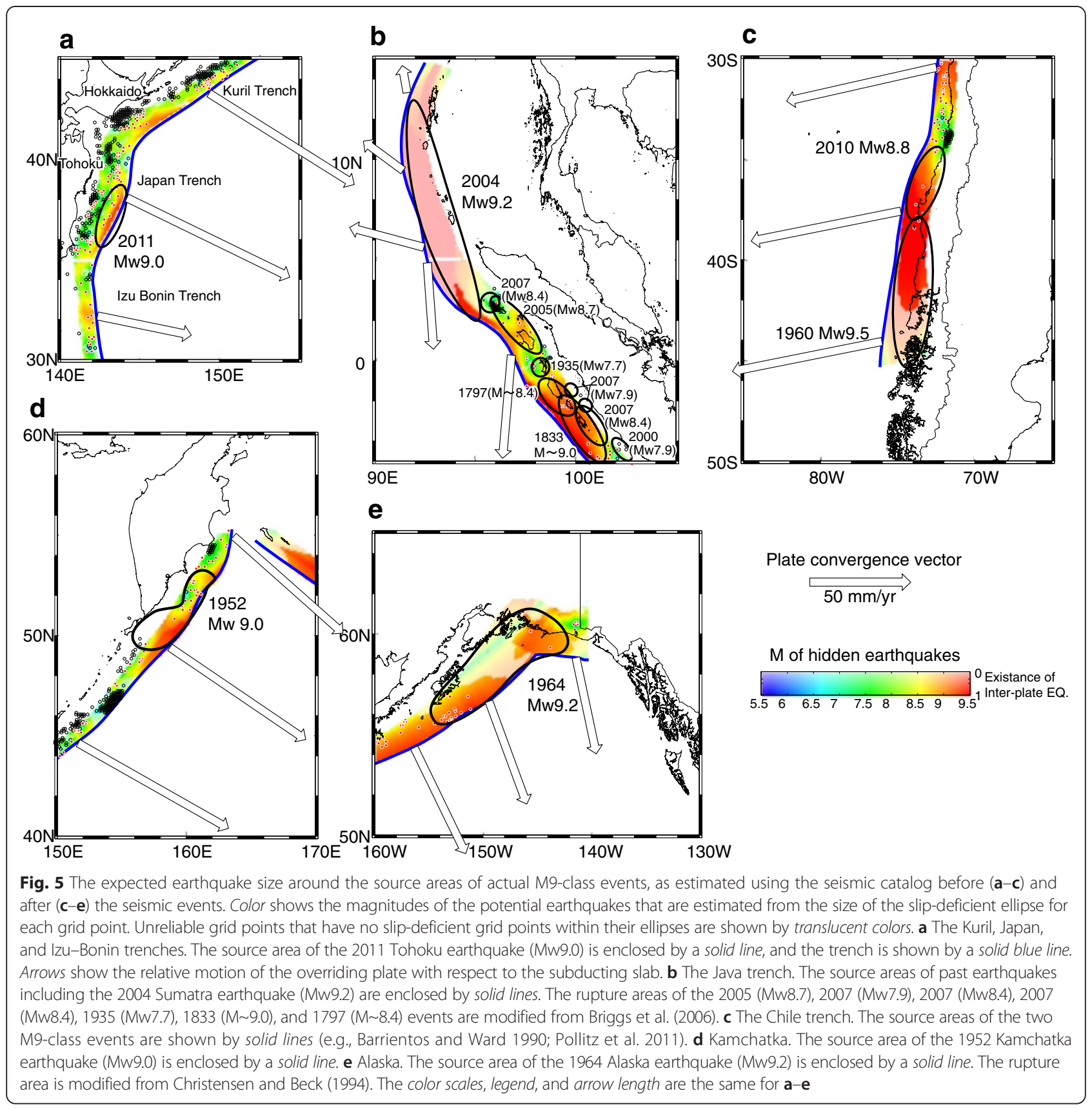

\section{Spatial extents of "slip-deficient" grid points in present global subduction zones}

We applied the same procedure as that described above to circum-Pacific subduction zones using earthquake catalogs prior to 2011. The rate of relative plate motion at each grid point was derived from Galgana et al. (2007), Ohkura (2013), and Bird (2003). The catalog period is from 1900 to 2010, except for the Ecuador-Peru-Chile trench, for which we chose a start time of 1907 in order to evaluate the rupture area of the 1906 Ecuador earthquake (M8.8). In Fig. 6, the areas in which calculated magnitudes exceed 9.0 are enclosed by ellipses. In addition to the six known M9-class source areas, the following 25 fault segments are enclosed by ellipses in Fig. 6: the border of the Kuril and Japan trenches; northern, central, and southern Ryukyu; southern Izu-Bonin; northern, central, and southern Mariana; western and central Aleutian; South Sandwich; northern, central, and southern Central America; western, central, and eastern South Java; Manila; Ecuador-Peru; Northern Chile; New Britain; New Hebrides; Tonga; and the northern and southern Kermadec trenches (Table 1). 
a

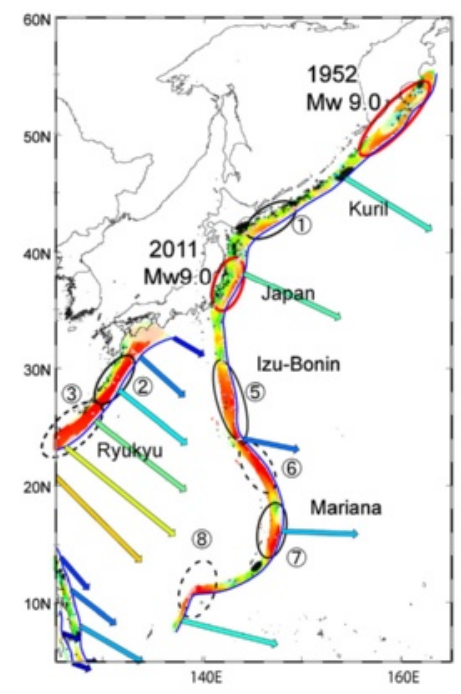

b
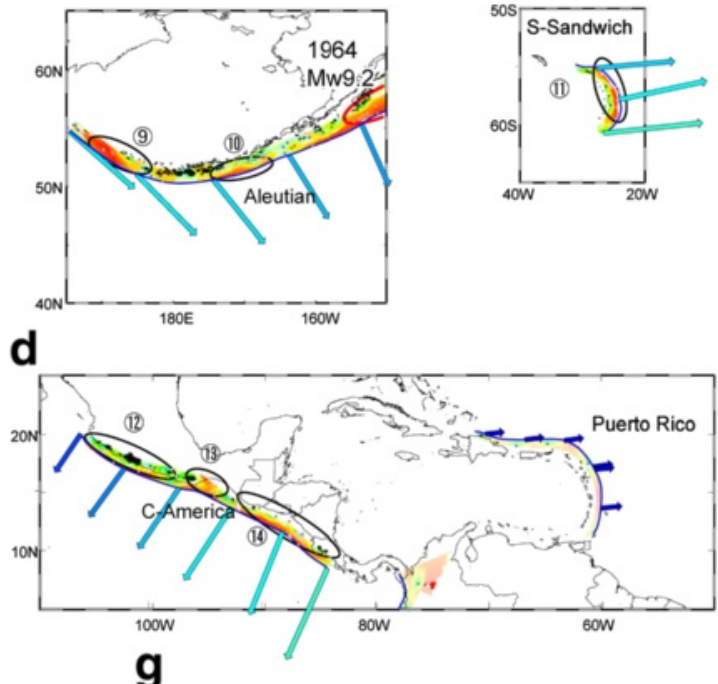

C

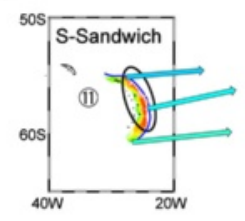

g e

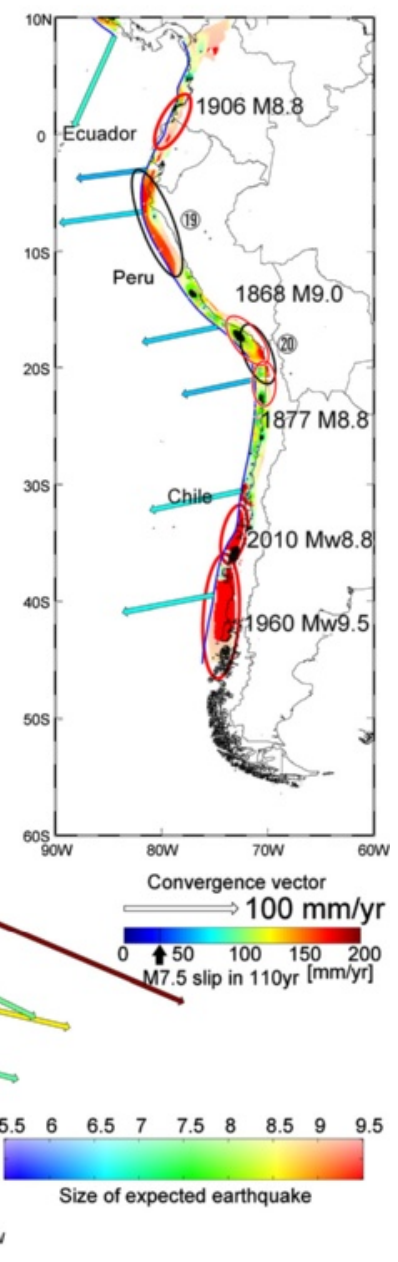

f
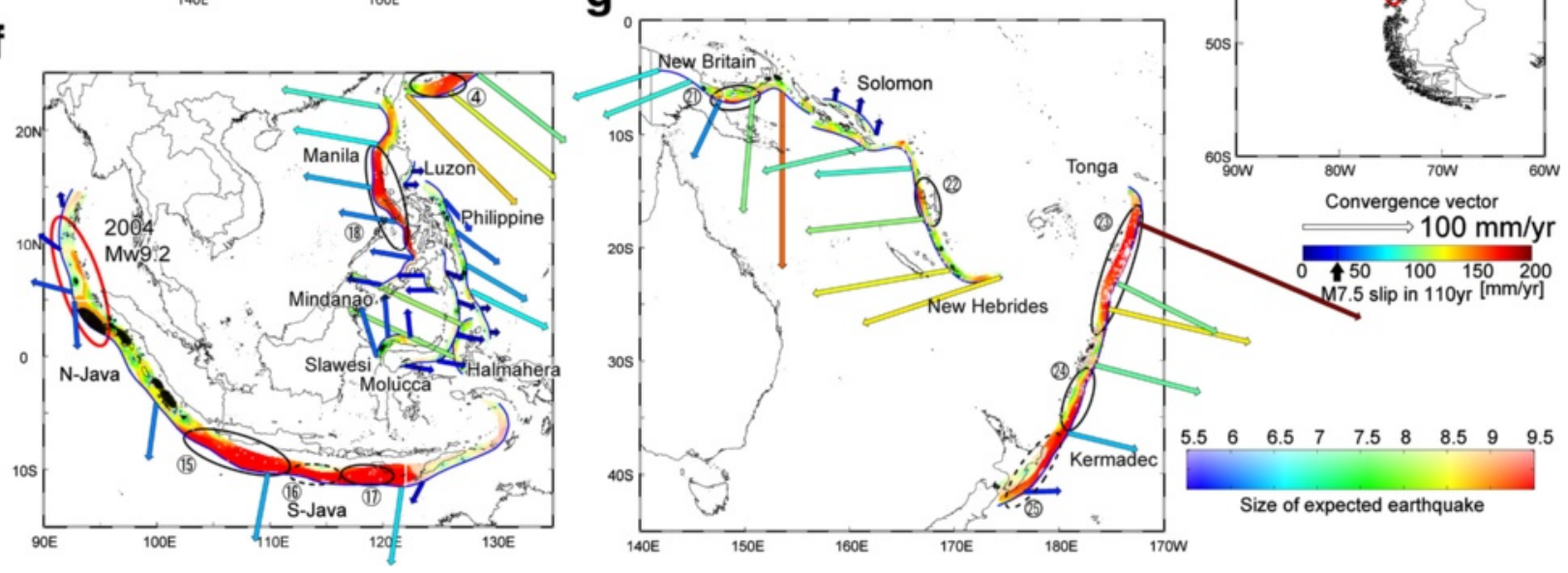

Fig. 6 Expected size distribution of hidden potential earthquakes in global subduction zones. Red colors correspond to larger magnitudes for the expected earthquakes. Areas with low reliability have translucent colors. The lengths and colors of the vectors show the convergence rate of the plate at the subduction zone (showing the displacement vector of the overriding plate). Red circles with white outlines and open circles denote slip-deficient and sufficiently slipping grid points, respectively. Solid and broken ellipses show categories A and B areas, respectively. a The Kuril, Japan, Izu-Bonin, Mariana, and Ryukyu trenches. The areas with expected magnitudes of $>9.0$ are indicated by numbered ellipses. The source areas of the 1952 Kamchatka (Mw9.0) and 2011 Tohoku (Mw9.0) earthquakes are enclosed by red ellipses. b The Aleutian trench. The source area of the 1964 Alaska earthquake (Mw9.2) is enclosed by a red ellipse. c The South Sandwich trench. d The Central America (C-America) and Puerto Rico trenches. e The Peru-Chile trench. The source areas of the huge 1960 and 2010 events are enclosed by red ellipses. f The North Java, South Java, Manila, East Philippine, Molucca, Halmahera, and Sulawesi trenches. The Manila trench and a huge area in the southern part of the Java trench show expected magnitudes of >9.0. Focal areas of the huge historical earthquakes that occurred in 1868 (M9.0), 1877 (M8.8), and 1906 (M8.8) are also shown. The areas for the 1868 and the 1877 events were derived from intensity distributions presented by Comte and Pardo (1991), and the area of the 1906 event is from Kanamori and McNally (1982). g The New Britain, Solomon, New Hebrides, Tonga, and Kermadec trenches

\section{Discussion}

\section{Validity of assumptions}

We first discuss the validity of the assumptions made in this study in order to categorize the calculated slipdeficient areas. We rate the reliability of these areas as follows: category A-strong candidate for strainaccumulated area; category B-a candidate with some uncertainty; and category $\mathrm{C}-\mathrm{a}$ minor candidate that does not show a large area of slip deficit and has a large uncertainty.

This study was based on the following assumptions:

1. Each interplate earthquake has a stick-slip patch around its centroid. Once a stick-slip patch is defined by an interplate earthquake, it will only slip by earthquake motion, not by creep 
Table 1 Subduction zone, plate identifiers and Euler poles/convergence rate

\begin{tabular}{|c|c|c|c|c|c|c|c|c|}
\hline Subduction zone & Plate pair & $\lambda,{ }^{\circ} \mathrm{N}$ & $\varphi,{ }^{\circ} \mathrm{E}$ & $\omega^{\circ} / \mathrm{Myr}$ & $\begin{array}{l}\text { Convergence rate }[\mathrm{mm} / \text { year] (/at } \\
\text { latitude/direction [deg]) }\end{array}$ & Author & \# in Fig. 7 categories: A-C & $\begin{array}{l}\text { Uncertain because (S) convergence } \\
\text { is short/(N) no interplate earthquakes }\end{array}$ \\
\hline Kuril-Japan & $\mathrm{PA}-\mathrm{OK}$ & -55.42 & 97.14 & 0.845 & - & Bird 2003 & (1) A & $-{ }^{\mathrm{b}}$ \\
\hline Ryukyu & PS-ON & -36.69 & -40.42 & 3.603 & - & Bird 2003 & (2) $\mathrm{A}$, (3) $\mathrm{B},(4) \mathrm{A}$ & $-^{c}$ \\
\hline Izu-Bonin & PA-PS & 1.20 & 134.20 & 1.000 & - & Bird 2003 & (5) $\mathrm{A}$ & - \\
\hline Mariana & PA-MA & -43.78 & -30.80 & 1.278 & - & Bird 2003 & (6) $\mathrm{B},(7) \mathrm{A}, 8) \mathrm{B}$ & - \\
\hline Aleutians & PA-NA & -48.71 & 101.83 & -0.749 & - & Bird 2003 & (9) A, (10) A & $-{ }^{d}$ \\
\hline South Sandwich & SA-SW & 36.60 & 150.40 & 1.880 & - & Bird 2003 & (11) A & - \\
\hline C-America $\left(92^{\circ} \mathrm{W}<\right)$ & CO-NA & 27.88 & -120.68 & 1.357 & - & Bird 2003 & (12) A, (13)A & - \\
\hline C-America $\left(<92^{\circ} \mathrm{W}\right)$ & $\mathrm{CO}-\mathrm{CA}$ & 21.63 & -121.36 & 1.256 & - & Bird 2003 & (14) $A$ & - \\
\hline Puerto Rico $\left(17^{\circ} \mathrm{N}<\right)$ & $\mathrm{NA}-\mathrm{CA}$ & -78.41 & 82.54 & 0.175 & - & Bird 2003 & - & $S / N$ \\
\hline Puerto Rico $\left(<17^{\circ} \mathrm{N}\right)$ & SA-CA & -51.50 & 114.30 & 0.272 & - & Bird 2003 & - & $\mathrm{S} / \mathrm{N}$ \\
\hline Cascadia & $J F-N A$ & -20.71 & 67.78 & 0.769 & - & Bird 2003 & - & N \\
\hline Halmahera & $\mathrm{SU}-\mathrm{BH}$ & 42.79 & -79.05 & 1.24 & - & Bird 2003 & - & - \\
\hline Philippine $\left(<5^{\circ} \mathrm{N}\right)^{\mathrm{a}}$ & PS- & & - & & $9 / 2^{\circ} \mathrm{N} / \mathrm{N} 90^{\circ} \mathrm{W}$ & Ohkura 2013 & - & S \\
\hline Philippine $\left(5^{\circ} \mathrm{N}<\right)^{a}$ & PS- & & - & & $40 / 13^{\circ} \mathrm{N} / \mathrm{N} 45^{\circ} \mathrm{W} 62 / 8^{\circ} \mathrm{N} / \mathrm{N} 60^{\circ} \mathrm{W}$ & Ohkura 2013 & C & - \\
\hline Luzon $^{a}$ & PS- & & - & & $9 / 17^{\circ} \mathrm{N} / \mathrm{N} 90^{\circ} \mathrm{W} 15 / 15^{\circ} \mathrm{N} / \mathrm{N} 90^{\circ} \mathrm{W}$ & Ohkura 2013 & - & S \\
\hline Molucca $\left(<2^{\circ} \mathrm{N}\right)^{\mathrm{a}}$ & $-S U$ & & - & & $26 / 1^{\circ} \mathrm{N} / \mathrm{N} 80^{\circ} \mathrm{W}$ & Ohkura 2013 & - & S \\
\hline Molucca $\left(2^{\circ} \mathrm{N}<\right)^{\mathrm{a}}$ & $-S U$ & & - & & $17 / 5^{\circ} \mathrm{N} / \mathrm{N} 70^{\circ} \mathrm{W}$ & Ohkura 2013 & - & S \\
\hline Mindanao ${ }^{a}$ & SU- & & - & & $25 / 6^{\circ} \mathrm{N} / \mathrm{N} 90^{\circ} \mathrm{E}$ & Ohkura 2013 & - & S \\
\hline Sulawesi & SU-MS & 2.10 & 126.20 & 3.40 & - & Bird 2003 & - & - \\
\hline South Java $\left(<5^{\circ} \mathrm{N},<122^{\circ} \mathrm{E}\right)$ & $A U-S U$ & 1.85 & 60.18 & 0.709 & - & Bird 2003 & (15) $A$, (16) $B,(17) A$ & - \\
\hline South Java $\left(122^{\circ} \mathrm{E}<\right)$ & $\mathrm{AU}-\mathrm{TI}$ & 14.12 & -50.54 & 1.743 & - & Bird 2003 & - & $S / N$ \\
\hline North Java $\left(5^{\circ} \mathrm{N}<\right)$ & $\mathrm{IN}-\mathrm{BU}$ & 13.49 & 94.79 & 2.349 & - & Bird 2003 & - & $-{ }^{e}$ \\
\hline Manila & SU- & & & & $62 / 5^{\circ} \mathrm{N} / \mathrm{N} 100^{\circ} \mathrm{E} 37 / 8^{\circ} \mathrm{N} / \mathrm{N} 100^{\circ} \mathrm{E}$ & Ohkura 2013 & (18) A & - \\
\hline Ecuador-Peru $\left(<4^{\circ} \mathrm{S}\right)$ & NZ-ND & 52.30 & -91.08 & 0.661 & - & Bird 2003 & - & - \\
\hline 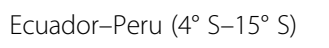 & NZ-SA & 55.96 & -94.01 & 0.725 & - & Bird 2003 & (19) A & - \\
\hline Peru-Chile $\left(15^{\circ} \mathrm{S}-21^{\circ} \mathrm{S}\right)$ & NZ-AP & 79.02 & -172.70 & 0.626 & - & Bird 2003 & (20) A & - \\
\hline Chile $\left(21^{\circ} \mathrm{S}<\right)$ & NZ-SA & 55.96 & -94.01 & 0.725 & - & Bird 2003 & - & $-{ }^{f}$ \\
\hline Solomon & NB-PA & 4.00 & -41.00 & 0.330 & - & Bird 2003 & - & S \\
\hline New Britain $\left(<147^{\circ} \mathrm{E}\right)$ & WL-NB & 28.71 & 130.35 & 1.261 & - & Bird 2003 & - & - \\
\hline
\end{tabular}


Table 1 Subduction zone, plate identifiers and Euler poles/convergence rate (Continued)

\begin{tabular}{|c|c|c|c|c|c|c|c|c|}
\hline New Britain (147 E-154) & $W L-S B$ & -5.73 & 144.86 & 9.736 & - & Bird 2003 & (21) $A$ & - \\
\hline New Britain $\left(154^{\circ} \mathrm{E}<\right)$ & PS-SU & -59.99 & -1.24 & 1.047 & - & Bird 2003 & - & - \\
\hline New Hebrides $\left(<14^{\circ} \mathrm{S}\right)$ & $A U-P A$ & 60.08 & 1.74 & 1.074 & - & Bird 2003 & - & - \\
\hline Tonga & PA-TO & -28.81 & -177.74 & 9.30 & - & Bird 2003 & (23) $\mathrm{A}$ & - \\
\hline Kermadec & PA-KE & -47.52 & 176.89 & 2.831 & - & Bird 2003 & (24) $\mathrm{A},(25) \mathrm{B}, \mathrm{C}\left(\sim 30^{\circ} \mathrm{S}\right)$ & - \\
\hline
\end{tabular}

$\lambda$ and $\varphi$ are the latitude and longitude of the Euler poles. Plate abbreviations follow Bird (2003): PA = Pacific, OK = Okhotsk, PS = Philippine Sea, MA $=$ Mariana, NA $=$ North America, $S A=S$ South America, SW $=$ Sandwich, $\mathrm{CO}=$ Cocos, $\mathrm{CA}=$ Caribbean, JF = Juan de Fuca, SU = Sunda, BH = Birds Head, MS = Molucca Sea, AU = Australia, TI = Timor, BU = Burma, NZ = Nazca, ND = North Andes, AP = Altiplano, NB = North Bismarck, WL = Woodlark, $\mathrm{NH}=$ New Hebrides, $\mathrm{TO}=$ Tonga, $\mathrm{KE}=$ Kermadec

bonvergence rate is applied rather than the plate rotation parameters

Experienced two great earthquakes (1952, M9.0; 2011, M9.0)

${ }^{\mathrm{c}} \mathrm{N}$ for the Nankai Trough-northern extension of the Ryukyu trench

${ }^{d}$ Experienced one great earthquake (1964, M9.2)

Experienced one great earthquake (2004, M9.2)

${ }^{\mathrm{f}}$ Experienced two great earthquakes (1960, M9.5; 2010, M8.8) 
2. Stick-slip patches within the rupture area of potential huge earthquakes should accumulate a slip deficit during the interseismic period. Grid points that have slip deficits larger than half of the relative plate displacement during this period are regarded as slip-deficient grid points. In contrast, grid points with cumulative slips larger than half of the slip expected from the relative plate motion are regarded as sufficiently slipping grid points. Areas that include slip-deficient grid points and that do not include any sufficiently slipping points are regarded as accumulating strain

3. The magnitude of each hidden potential earthquake is calculated from the size of the area that contains slip-deficient grid points and that contains no sufficiently slipping grid points, rather than from the slip-deficit value

4. The stick-slip patches are defined only for interplate earthquakes listed in the GCMT catalog. All earthquakes that slipped on the stick-slip patches prior to the GCMT catalog are regarded as interplate earthquakes

5. The accumulated relative plate displacement during the period of investigation is sufficient to evaluate slip deficit

The first and second assumptions are the basic principles of this study and are supported by previous studies, as described in the "Introduction" section. Since the results of the tests conducted for the source areas of the six huge earthquakes that have occurred during the past 110 years support these basic principles, we consider that these assumptions are valid. It could be argued that stick-slip patches for M7-class earthquakes should be detected by the geodetic observations if the patches are locked during the interseismic period, but this is not always the case. For example, geodetic studies of the interseismic period around the Tohoku-Oki rupture area (e.g., Loveless and Meade 2011) show only one large coupling area around the centroid of the Tohoku-Oki earthquake. Loveless and Meade (2011) carried out a checkerboard test and showed that it is difficult to resolve off-shore locked patches with diameters of $<100 \mathrm{~km}$ using geodetic inversions, as all stations are located on-shore. Conversely, results from small repeating earthquakes do show coupling around some past M7-class earthquakes (Uchida and Matsuzawa 2013).

The third assumption could lead to large errors because one slip-deficient grid point combined with a vast surrounding aseismic region can generate large areas of apparent accumulated strain. In terms of the fourth assumption, the misclassification of intraplate earthquakes as interplate earthquakes would result in an overestimate of the total seismic slip. The fifth assumption is also critical, as the short duration of the investigated periods results in large uncertainties in determining whether the plate motion is sufficient for the analysis. The impact of these three assumptions on the uncertainty of the results is evaluated below.

First, we discuss the case where a few slip-deficient grid points are surrounded by a vast aseismic region, which generates a large calculated apparent magnitude. We classified the areas showing a large calculated magnitude (as delineated by the ellipses in Fig. 6) into categories A and $\mathrm{B}$ based on the localization of slip-deficient grid points. Category A areas contain a good coverage of slip-deficient grid points and do not contain any vacant spaces larger than the rupture ellipse of a magnitude 9.0 earthquake on the plate boundary. The following 20 areas were classified as category A: the southern part of the Kuril trench; the northern part of the Ryukyu trench; the southern part of the Izu-Bonin trench; western and central Aleutian trench; the South Sandwich trench; northern, central, and southern Central America trench; western and eastern South Java trench; the Manila trench; the Ecuador-Peru trench; northern Chile trench; the New Britain trench; the New Hebrides trench; the Tonga trench; and northern Kermadec trench. It is probably that the interplate seismic slip in these areas is suppressed due to the locked regions that will likely be responsible for future huge earthquakes. The remaining five areas contain large vacant spaces equivalent to the rupture ellipses of M9.0 earthquakes and are recognized as category B: the central part of the Ryukyu trench; the northern and southern parts of the Mariana trench; central South Java trench; and southern Kermadec trench. For these areas, we cannot deny the possibility that the few "slip-deficient" grid points and the surrounding vast aseismic regions have generated the large calculated magnitudes. Although category A areas are relatively reliable, there is still some uncertainty in the calculated expected earthquake magnitudes, as older interplate earthquakes that occurred outside the defined stick-slip patches are ignored. In the Nankai Trough, though which is "unreliable" area, two M8-class interplate earthquakes that occurred in 1944 and 1946 are ignored in our analysis because no stick-slip patches were defined through the GCMT catalog calculations. We cannot discount the possible existence of such missed stick-slip (and sufficiently slipping) patches in the category A areas. In such a case, the magnitude of the hidden potential earthquake would be overestimated. However, significant overestimation is unlikely in subduction zones with high convergence rates because if M8 (not M9) is the largest capable event, such an event with a slip of $\sim 3 \mathrm{~m}$ should have occurred within the past 110 years.

Second, we evaluate the impact of misclassification of the earthquake mechanism. All earthquakes that occurred before the beginning of the GCMT catalog with slip areas 


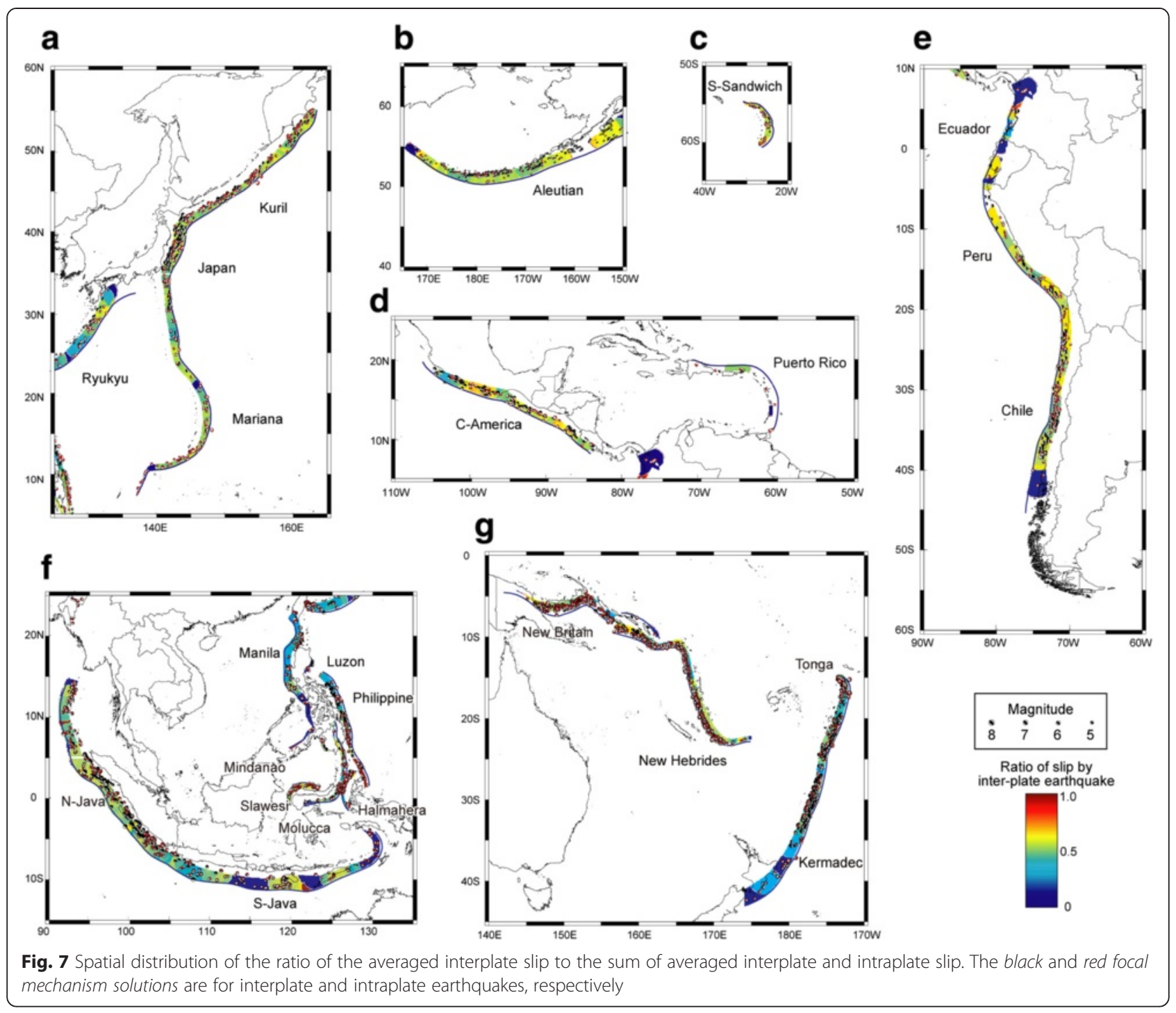

on the plate interface that include stick-slip grid points are considered to be interplate earthquakes, which should overestimate interplate cumulative slip to some extent. We evaluate the degree of this overestimation using the GCMT catalog for earthquakes that occurred after 1976. Figure 7 shows the spatial distribution of the ratio of the total slip of interplate earthquakes to the total slip of all earthquakes. The ratio $\lambda_{j}$ for the $j$ th grid point is calculated using all earthquakes within $220 \mathrm{~km}$ of the grid point:

$$
\lambda_{j}=\frac{\sum_{I} D_{I}}{\sum_{I} D_{I}+\sum_{K} D_{K}},
$$

where $D_{I}$ and $D_{K}$ represent $D_{\max }$ (Eq. 5) for each interplate and intraplate earthquake, respectively. The distance of $220 \mathrm{~km}$ corresponds to the long axis of the M9.0 stickslip patch. In this calculation, we omit the earthquakes with slips (from Eqs. 2, 3, 4, and 5) larger than their respective relative plate displacements over the 34 years of GCMT data used in this study. The inclusion of such large and rare earthquakes would cause the results to be unstable and unreliable. The resulting ratios are generally low in the Southwest Pacific (Fig. 7). Figure 7 shows that interplate earthquakes are not prevalent in the Ryukyu trench, most trenches around the Philippine Islands, and the southern Kermadec trench. Consequently, slip deficits based on these results would be underestimated. This is especially true around the Philippine Islands, where calculated magnitudes based on the spatial extent of slipdeficient grid points do not exceed 9.0 except for the Manila trench (Fig. 6e). Therefore, the calculated magnitude may be underestimated around the Philippines. In the Kermadec trench, the calculated magnitude exceeds 9.0 in the south but is smaller in the central part of the trench at $\sim 30^{\circ} \mathrm{S}$ and is therefore underestimated in this 
region. We categorize the areas in which the calculated magnitudes do not exceed 9.0 and interplate slip is less than half of the total slip as category C. Such areas include the northern Kermadec trench $\left(\sim 30^{\circ} \mathrm{S}\right)$ and the northern Philippine trench (Fig. 6e, g). This evaluation contains additional uncertainties due to the short duration of the test period using GCMT solutions.

Finally, we evaluate the uncertainty of the results due to the short duration of measurements of relative plate displacements. Regions with relatively low plate velocities have larger uncertainties in slip deficit. Figure 8 shows a schematic illustration of the slip history of a huge stickslip patch (M9) and surrounding smaller patches. The section of the hanging wall around the patch is dragged by the subducting slab (via the stick-slip patch) and its motion relative to the subducting slab is consequently reduced. Therefore, the cumulative seismic slip of the surrounding small stick-slip patches becomes smaller due to this reduced relative motion. Our analysis is designed to detect this slip-deficient area by summing the seismic slip (white areas in Fig. 8); however, we cannot extract the hidden source area using earthquakes with slips larger than the relative plate displacement (Fig. 8b). If we focus on a stick-slip patch with a unit slip smaller than the cumulative plate motion within a given period, the absence of seismic slip might indicate that some larger stick-slip patches also exist behind. However, if we focus on a stick-slip patch with a slip larger than cumulative plate motion, neither the absence nor the presence of seismic slip would provide information on hidden potential earthquakes because the occurrence of an earthquake within the given period is simply a matter of probability. It would be ideal to make observations until the cumulative relative plate motion exceeds the slip of the stick-slip patch used as the slip-deficit indicator. However, it is not easy to know how much displacement of the relative plate motion is sufficient for the estimation because we do not know the size of the potential earthquakes hidden behind the apparent seismicity. As a practical measure of the sufficiency of the period, we compare the total relative plate motion over 110 years with the seismic slip of a single M7.5 earthquake for various subduction zones. Peak slip for an M7.5 earthquake is $4.28 \mathrm{~m}$. Relative plate motions smaller than this are shown in dark blue in Fig. 6 and include those at the Puerto Rico, Solomon, and Northern Java trenches, as well as the trenches around the Philippine Islands, except for the Manila trench. In these regions, the estimated slip-deficit distribution should be affected by relatively small earthquakes and the uncertainties in the results are large compared with other regions. In Table 1, these areas, which display large uncertainties in slip deficit due to small relative plate motions, are listed as uncertain areas, in addition to the Nankai Trough in Japan and Cascadia in North America where no stick-slip patches have been defined.
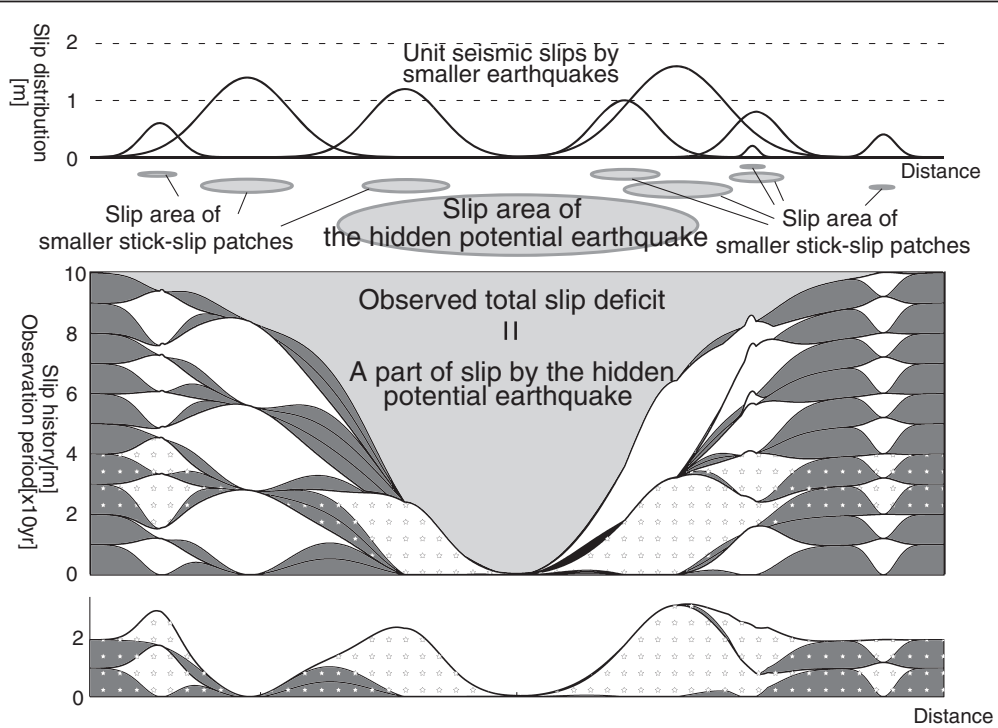

Fig. 8 Schematic illustration of the interplate slip model. Top: locations of stick-slip patches on the plate boundary (ellipses) and their amount of seismic slip (Gaussian curves) by respective earthquakes. Eight stick-slip patches have their own earthquake sizes. A stick-slip patch on the plate boundary has the potential to produce an earthquake with an area and slip much larger than those of the other eight patches. Middle: slip history along the plate boundary at a constant time interval. Seismic and aseismic slip are shown by white and dark gray colors, respectively. Each stick-slip patch releases its slip deficit mainly by seismic slip. The accumulated slip increases with increasing distance from the center of the hidden potential stick-slip patch. In this case, each time interval corresponds to a relative plate motion of $1 \mathrm{~m}$. The area covered by small stars corresponds to the slip during periods from time steps \#2 to \#4. Bottom: Slip history for the period from time steps \#2 to \#4 extracted from the middle figure. The slip deficit due to the hidden potential earthquake is not apparent 
Focal areas of M9-class earthquakes in the past 110 years As described above, we developed a method of evaluating strain accumulation on subduction plate boundaries and we applied this method to the six known M9-class earthquakes that have occurred in the past 110 years. We also applied the method to circum-Pacific subduction zones and calculated earthquake magnitudes from the spatial extents of slip-deficient areas. In this section we discuss the correlation between the slip-deficient area and the rupture area of the known M9-class earthquakes. The areas that were calculated from the catalog to have magnitudes of $\geq 9$ prior to the 2011 Tohoku, 2004 Sumatra, and 2010 Chile M9-class interplate earthquakes correlate closely with the rupture areas of the actual M9-class events (Fig. 5). The rupture area of the 2004 Sumatra earthquake is unreliable because the absence of interplate thrust earthquakes in this region during the time when GCMT solutions are available means that we cannot judge whether the area contains a stick-slip patch. In contrast, the results around the source areas of the 2011 Tohoku and the 2010 Chile earthquakes are regarded as being highly reliable because these areas contain widespread stick-slip grid points with slip deficits compared with the relative plate motions. Large magnitudes are estimated in the southern extension of the rupture area of the 2004 Sumatra earthquake from $5^{\circ} \mathrm{S}$ to $5^{\circ} \mathrm{N}$ (Fig. 5b). In this area, huge earthquakes occurred in 1833 ( M9.0; Briggs et al. 2006) and 1797 ( M8.4), which correspond to the area with the large calculated magnitude. Six M8-class events have also occurred since 2004 with source areas that correspond to those of the expected large-magnitude earthquakes.

The slip deficits after the 1960 Chile, 1952 Kamchatka, and 1964 Alaska M9-class events evaluated from the catalog also show good correlations between the calculated large-magnitude areas and the rupture areas (Fig. 5c, e). This result reflects a lull in seismicity after an almost full release of seismic moment around the rupture area and may also suggest that the strong and/or large stick-slip patches capable of producing M9-class earthquakes are persistent and recover their locking behavior immediately after huge interplate earthquakes.

\section{Correspondence between historical huge events and the areas where huge earthquakes are expected from the slip-deficit analysis}

Our result over the circum-Pacific region using the catalog prior to 2011 shows 25 category A and B segments (Fig. 6). Historical studies point to several more M9-class interplate earthquakes than the six huge events shown in Fig. 5. For example, the 1700 Cascadia (M9.0), 1868 Peru (M9.0), 1877 North Chile (M8.8), and 1906 Ecuador (M8.8) earthquakes are listed as $\geq$ M8.8 by the USGS (http://earthquake.usgs.gov/earthquakes/world/historical_ mag.php last updated November 25, 2015). For Cascadia, our method cannot evaluate the slip deficit because no interplate earthquakes occurred during the time covered by the GCMT catalog. Instead, our results indicate that the region along the Ecuador-Peru-Chile trench is classified as category A. Figure $6 \mathrm{f}$ shows our result along the trench, as estimated from the catalog for the period from 1907 to 2010 together with the rupture areas of the historical M9-class earthquakes. Around the rupture areas of the 1906 M8.8, 1868 M9.0, and 1877 M8.8 earthquakes, our analysis anticipates M9 or larger earthquakes, although the spatial extents and the locations of these events do not agree exactly with those of the actual earthquakes. The reliability of the expected magnitude around the 1906 source area is low because only a few stick-slip grid points exist in this region. The area with expected magnitudes of >M9 for the 1868 and 1877 events is localized along only one border of the actual rupture areas, which were widely spread along the trench.

Along the Ecuador-Peru trench, a huge area extending from $2^{\circ} \mathrm{S}$ to $10^{\circ} \mathrm{S}$ has a large calculated magnitude. Historical records give no indication that a great earthquake has occurred in this region during the last 400 years (Kelleher 1972). Although McCann et al. (1979) classified this region as the site of no great earthquakes based on its earthquake history, our results show that it contains many stick-slip patches with cumulative seismic slips smaller than the relative plate motion, indicating that this region is a likely location of future M9-class events.

\section{Subduction with back-arc spreading}

Our results show large expected magnitudes of $>9.0$ in several subduction zones that have back-arc spreading, including the Mariana, Ryukyu, South Sandwich, and IzuBonin trenches, which are classified as Mariana-type trenches. Uyeda (1982) described the differences between Mariana-type and Chilean-type trenches and pointed out that earthquakes with magnitudes significantly larger than 8.0 do not occur in Mariana-type trenches. Scholz and Campos (1995) evaluated this relationship quantitatively and proposed that seismic coupling in Mariana-type trenches is suppressed due to a reduction in the normal force at the plate interface, which is related to the absolute velocity of the upper plate and the length of the subducting slab. The seismic coupling correlates with the calculated normal force, which was explained in the context of the rate- and state-dependent friction law (e.g., Ruina 1983), which states that a reduction in normal force increases the sliding stability of the interface. We should note that their theory only evaluates the likelihood that a plate interface is a region of stable slip, and it does not exclude the possibility that great earthquakes may occur if unstable sliding patches exist. Our results show that 
stick-slip patches with cumulative seismic slips smaller than the relative plate motions occur in the Mariana trench and other Mariana-type trenches. These patches should compensate for the slip deficit by slipping seismically in the future, unless the frictional properties of these patches change from stick-slip to stable slip; we cannot exclude the possibility of M9-class earthquakes in these regions.

\section{Frequency of M9-class earthquakes}

Seismologists have attempted to correlate the history of earthquakes over the past century with subduction zone properties such as convergence rate, slab age, type of overriding plate, and fault temperature, in order to understand the limits on earthquake size. For example, Ruff and Kanamori (1980) showed significant correlations between characteristic earthquake size in subduction zones and the convergence rates and ages of the subducting slab. They suggested that a young and fastmoving slab would be subducted into the mantle at a lower angle and would stick more strongly to the overriding plate, resulting in larger earthquakes. However, later studies (e.g., Pacheco et al. 1993; Stein and Okal 2007) that incorporated more recent earthquake data and improved data show weaker correlations than those proposed by Ruff and Kanamori (1980). Furthermore, the underlying idea that some subduction zones may never produce an M9-class earthquake has been called into question with the occurrence of the 2004 Sumatra Mw9.2 and the 2011 Tohoku Mw9.0 earthquakes. Our study does not consider the physical properties of subduction zones and is based purely on the idea of slip deficit. As a result, the calculated magnitudes in 31 areas exceed M9.0. This number may be considered too high in terms of the number of areas that are likely to be

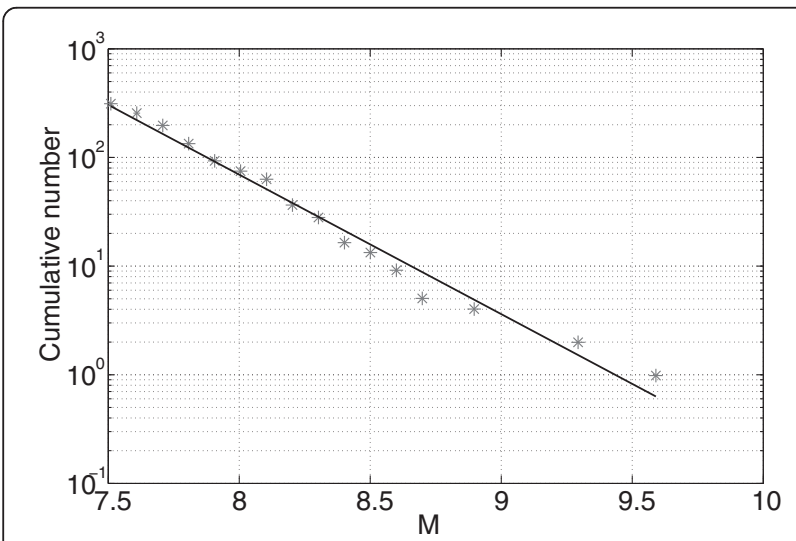

Fig. 9 Magnitude-cumulative frequency curve for earthquakes of $>M 7.5$ in 1900-2010 derived from the ISC-GEM catalog. The asterisks show actual data and the solid line is the linear fit. The 2011 Tohoku earthquake (Mw9.0) is not listed, and the 2010 Chile earthquake (Mw8.8) is listed as M8.3 in the catalog candidates for M9-class earthquakes. However, it should not be surprising from a statistical viewpoint. Figure 9 shows the magnitude-frequency relationship for earthquakes occurring between 1900 and 2010 with magnitudes of $>7.5$. For magnitudes between 7.5 and 9.5, the relationship seems to follow the Gutenberg-Richter law (GR law), suggesting that M9-class earthquakes are not unusual ones in global subduction zones.

If we accept that the observed frequency of M9-class events, at six in the past 110 years, is reasonable in terms of the GR law, we can assume that the same number of events will occur each 110 years. Upcoming M9class events should occur in regions other than the six known areas because the recurrence interval of each M9-class event should be longer than several hundred years. Consequently, it would not be surprising if the number of areas capable of producing an M9-class earthquake is several times greater than this value of six. Indeed, 31 such areas are defined by our study, which is within the range of this estimate.

\section{Conclusions}

We evaluated the interplate slip deficit for the 110 years prior to the 2004 Sumatra (Mw9.2), 2010 Chile (Mw8.8), and 2011 Tohoku (Mw9.0) M9-class earthquakes from a seismic catalog. We found that large areas with sizes equivalent to source areas of M9.0 events around the rupture areas of the earthquakes accumulated slip deficit. We also investigated the slip deficit that accumulated after the 1952 Kamchatka (Mw9.0), 1960 Chile (Mw9.5), and 1964 Alaska (Mw9.2) earthquakes and found that slip deficit accumulated around the rupture areas after the occurrence of the M9-class earthquakes. We applied the same approach to global subduction zones and found that 31 regions, including the 6 listed above, show slip deficits over large areas equivalent to the size of an M9-class earthquake source area.

Competing interests

The authors declare that they have no competing interests.

Authors' contributions

R. Ikuta initiated the idea of slip-deficit evaluation using cumulative seismic slip. Y. Kurokawa carried out the feasibility studies. Yuta Mitsui and M. Ando analyzed slip-deficit data and evaluated the results of this study. All authors read and approved the final manuscript.

\section{Acknowledgements}

We are grateful to J. Loveless and T. Matsuzawa for critical reviews and encouraging comments that improved the manuscript. We thank the Global CMT project and the International Seismological Center (ISC) for providing the earthquake catalog. The manuscript was improved following helpful discussions on slip-deficit distribution with Y. Morishita, T. Watanabe, and K. Yamaoka.

\section{Author details}

${ }^{1}$ Graduate School of Science and Technology, Shizuoka University, Shizuoka, Japan. ${ }^{2}$ Graduate School of Environmental Science, Nagoya University, 
Nagoya, Japan. ${ }^{3}$ Center for Integrated Research and Education of Natural Hazards, Shizuoka University, Shizuoka, Japan.

Received: 18 December 2014 Accepted: 24 November 2015 Published online: 02 December 2015

\section{References}

Aki K (1966) Generation and propagation of $\mathrm{G}$ waves from the Niigata earthquake of June 16, 1964. Part 2. Estimation of earthquake moment, released energy, and stress-strain drop from the $\mathrm{G}$ wave spectrum. Bull Earth Res Inst 44:73-88

Barrientos SE, Ward SN (1990) The 1960 Chile earthquake: inversion for slip distribution from surface deformation. Geophys J Int 103:589-598

Bird P (2003) An updated digital model of plate boundaries. Geochem Geophys Geosyst 4(3):1027. doi:10.1029/2001GC000252

Blaser L, Kruger F, Ohmberger M, Scherbaum F (2010) Scaling relations of earthquake source parameter estimates with special focus on subduction environment. Bull Seis Soc Am 100(6):2914-2926

Briggs RW, Sieh K, Meltzner AJ, Natawidjaja D, Galetzka J, Suwargadi B et al (2006) Deformation and slip along the Sunda megathrust in the Great 2005 Nias-Simeulue Earthquake. Science 311:1897-1901

Christensen DH, Beck SL (1994) The rupture process and tectonic implications of the Great 1964 Prince William Sound Earthquake. PureAppl Geophys 142:29-53

Comte D, Pardo M (1991) Reappraisal of great historical earthquakes in the Northern Chile and Southern Peru seismic gaps. Nat Hazards 4:23-44

Dieterich JH (1979) Modeling of rock friction 1. Experimental results and constitutive equations. J Geophys Res 84(B5):2161-21681

Dziewonski AM, Chou T-A, Woodhouse JH (1981) Determination of earthquake source parameters from waveform data for studies of global and regional seismicity. J Geophys Res 86:2825-2852. doi:10.1029/JB086iB04p02825

Ekström G, Nettles M, Dziewonski AM (2012) The global CMT project 2004-2010: centroid-moment tensors for 13,017 earthquakes. Phys Earth Planet Inter 200-201:1-9. doi:10.1016/j.pepi.2012.04.002

Galgana G, Hamburger M, McCaffrey R, Corpuz E, Chen Q (2007) Analysis of crustal deformation in Luzon, Philippines using geodetic observations and earthquake focal mechanisms. Tectonophysics 432:63-87

Geller RJ (1976) Scaling relations for earthquake source parameters and magnitudes. Bull Seis Soc Am 66(5):1501-1523

Gudmundsson O, Sambridge M (1998) A regionalized upper mantle (RUM) seismic model. J Geophys Res 103(B4):7121-7136

Hanks T, Kanamori H (1979) A moment magnitude scale. J Geophys Res 84(B5):2348-2350

Hashimoto C, Noda A, Sagiya T, Matsu'ura M (2009) Interplate seismogenic zones along the Kuril-Japan trench inferred from GPS data inversion. Nat Geosci 2:141-144

Hirose H, Hirahara K, Kimata F, Fujii N, Miyazaki S (1999) A slow thrust slip event following the two 1996 Hyuganada earthquakes beneath the Bungo Channel, southwest Japan. Geophys Res Lett 26(21):3237-3240

Hirth G, Kohlstedt D (2003) Rheology of the upper mantle and the mantle wedge: a view from the experimentalists, inside the subduction factory. Geophys Monogr Ser 138:83-105. doi:10.1029/138GM06

Igarashi T, Matsuzawa T, Hasegawa A (2003) Repeating earthquakes and interplate aseismic slip in the northeastern Japan subduction zone. J Geophys Res 108(B5):2249. doi:10.1029/2002JB001920

Ikuta R, Satomura M, Fujita A, Shimada S, Ando M (2012) A small persistent locked area associated with the 2011 Mw9.0 Tohoku-Oki earthquake, deduced from GPS data. J Geophys Res 117, B11408. doi:10.1029/2012JB009335

Ito T, Yoshioka S, Miyazaki S (2000) Interplate coupling in northeast Japan deduced from inversion analysis of GPS data. EarthPlanet Sci Lett 176:117-130

Kanamori H, McNally KC (1982) Variable rupture mode of the subduction zone along the Ecuador-Colombia coast. Bull Seis Soc Am 72(4):1241-1253

Kelleher JA (1972) Rupture zones of large South American earthquakes and some predictions. J Geophys Res 77(11):2087-2103

Loveless JP, Meade BJ (2010) Geodetic imaging of plate motions, slip rates, and partitioning of deformation in Japan. J Geophys Res 115, B02410. doi:10.1029/2008JB006248

Loveless JP, Meade BJ (2011) Spatial correlation of interseismic coupling and coseismic rupture extent of the $2011 \mathrm{MW}=9.0$ Tohoku-oki earthquake. Geophys Res Lett 38, L17306. doi:10.1029/2011GL048561

Matsuzawa T, Igarashi T, Hasegawa A (2002) Characteristic small earthquake sequence off Sanriku, northeastern Honshu, Japan. Geophys Res Lett 29(11):1543. doi:10.1029/2001GL014632
McCann WR, Nishenko SP, Sykes LR, Krause J (1979) Seismic gaps and plate tectonics: seismic potential for major boundaries. Pure Appl Geophys 117:1082-1147

Mochizuki K, Yamada T, Shinohara M, Yamanaka Y, Kanazawa T (2008) Weak interplate coupling by seamounts and repeating $M \sim 7$ earthquakes. Science 321:1194-1197

Murotani S, Kikuchi M, Yamanaka Y (2004) Rupture processes oflarge Fukushima-Oki earthquakes in 1938(II) (in Japanese), paper presented at Fall Meeting 2004. Seismological Society of Japan, Fukuoka

Murotani S, Miyake H, Koketsu K (2008) Scaling of characterized slip models for plate-boundary earthquakes. Earth Planets Space 60:987-991

Nishimura T, Hirasawa T, Miyazaki S, Sagiya T, Tada T, Miura S et al (2004) Temporal change of interplate coupling in northeastern Japan during 1995-2002 estimated from continuous GPS observations. Geophys J Int 157:901-916

Ohkura T (2013) GPS observation in Mindanao, Philippine-for evaluation of earthquake potential, Abstract for Japan Geoscience Union 2013 Meeting., S-SS34-P11 (in Japanese)

Pacheco JF, Sykes LR, Sholz CH (1993) Nature of seismic coupling along simple plate boundaries of the subduction type. J Geophys Res 98(B8):14,133-14,159

Pollitz FF, Brooks B, Tong X, Bevis MG, Foster JH, Bürgmann R et al (2011) Coseismic slip distribution of the February 27, 2010 Mw 8.8 Maule, Chile earthquake. Geophys Res Lett 38, L09309. doi:10.1029/2011GL047065

Ruff L, Kanamori H (1980) Seismicity and the subduction process. Phys Earth Planet Int 23:240-252

Ruina A (1983) Slip instability and state variable friction laws. J Geophys Res 88(B12):10,359-10,370

Scholz CH (1998) Earthquakes and friction laws. Nature 391:37-42

Scholz CH, Campos J (1995) On the mechanism of seismic decoupling and back arc spreading at subduction zones. J Geophys Res 100(B11):22,103-22,115

Stein S, Okal EA (2007) Ultralong period seismic study of the December 2004 Indian Ocean earthquake and implications for regional tectonics and the subduction process. Bull Seis Soc Am 97(1A):S279-S295

Storchak DA, Di Giacomo D, Bondár I, Engdahl ER, Harris J, Lee WHK et al (2013) Public release of the ISC-GEM global instrumental earthquake catalogue (1900-2009). Seismol Res Lett 84:810-815

Suwa Y, Miura S, Hasegawa A, Sato T, Tachibana K (2006) Interplate coupling beneath NE Japan inferred from three-dimensional displacement field. J Geophys Res. doi:10.1029/2004JB003203

Syracuse EM, Abers GA (2006) Global compilation of variations in slab depth beneath arc volcanoes and implications. Geochem Geophys Geosyst 7 , Q05017. doi:10.1029/2005GC001045

Uchida N, Matsuzawa T (2013) Pre- and postseismic slow slip surrounding the 2011 Tohoku-oki earthquake rupture. Earth Planet Sci Lett 374:81-91

Uchida N, Matsuzawa T (2011) Coupling coefficient, hierarchical structure, and earthquake cycle for the source area of the 2011 off the Pacific coast of Tohoku earthquake inferred from small repeating earthquake data. Earth Planets Space 63:675-679

Uchida N, Matsuzawa T, Hasegawa A, Igarashi T (2005) Recurrence intervals of characteristic M4.8 \pm 0.1 earthquakes off-Kamaishi, NE Japan-comparison with creep rate estimated from small repeating earthquake data, Earth Planet. Sci Lett 233:155-165

Uyeda S (1982) Subduction zones: an introduction to comparative subductology. Tectonophysics 81:133-159

Wells DL, Coppersmith KJ (1994) New empirical relationships among magnitude, rupture length, rupture width, rupture area, and surface displacement. Bull Seis Soc Am 84(4):974-1002

Yamanaka Y, Kikuchi M (2003) Source process of the recurrent Tokachi-oki earthquake on September 26, 2003, inferred from teleseismic body waves. EarthPlanetsSpace 55:e21-e24

Yamanaka Y, Kikuchi M (2004) Asperity map along the subduction zone in northeastern Japan inferred from regional seismic data. J Geophys Res 109, B07307. doi:10.1029/2003JB002683 